\title{
Anxiolytic effect of methylene blue microinjected into the dorsal periaqueductal gray matter
}

R.W. de-Oliveira and F.S. Guimarães
Departamento de Farmacologia, Faculdade de Medicina de Ribeirão Preto, Universidade de São Paulo, Ribeirão Preto, SP, Brasil

\section{Correspondence \\ F.S. Guimarães \\ Departamento de Farmacologia \\ Faculdade de Medicina \\ de Ribeirão Preto, USP \\ 14049-900 Ribeirão Preto, SP \\ Brasil \\ Fax: + 55-16-633-2301 \\ E-mail: fsguimar@fmrp.usp.br}

Presented at the International Neurobiology Course, Faculdade de O dontologia de Ribeirão Preto, Universidade de São Paulo, Ribeirão Preto, SP, Brasil, May 20-27, 1998.

Research supported by FAPESP (No. 98/10639-7), FINEP and CNPq. R.W. de-O liveira and F.S. Guimarães are recipients of CAPES and $\mathrm{CNPq}$ fellowships, respectively.

Received December 9, 1998 Accepted September 8, 1999

\section{Abstract}

The dorsal periaqueductal gray (DPAG) has been implicated in the behavioral and autonomic expression of defensive reactions. Several results suggest that, along with GABA, glutamate and serotonin, nitric oxide (NO) may play a role in defense reactions mediated by this region. To further investigate this possibility we microinjected methylene blue (MB; 10,30 or $100 \mathrm{nmol} / 0.5 \mu \mathrm{l}$ ) into the DPAG of rats submitted to the elevated plus-maze test, an animal model of anxiety. $\mathrm{MB}$ has been used as an inhibitor of soluble guanylate cyclase (sGC) to demonstrate cGMP-mediated processes, and there is evidence that NO may exert its biological effects by binding to the heme part of guanylate cyclase, causing an increase in cGMP levels. The results showed that MB (30 nmol) significantly increased the percent of time spent in the open arms ( saline $=11.57 \pm 1.54, \mathrm{MB}=18.5 \pm 2.45$, $\mathrm{P}<0.05)$ and tended to do the same with the percentage of open arm entries (saline $=25.8 \pm 1.97, \mathrm{MB}=33.77 \pm 3.07, \mathrm{P}<0.10$ ), but did not change the number of enclosed arm entries. The dose-response curve, however, had an inverted $U$ shape. These results indicate that MB, within a limited dose range, has anxiolytic properties when microinjected into the DPAG.

The dorsal periaqueductal gray matter (DPAG) has been implicated in the behavioral and autonomic expression of defensive reactions (1). Electrical stimulation of this structure leads to flight responses with running, jumping and vocalization accompanied with cardiovascular changes (2). Drugs that enhance or mimic the inhibitory neurotransmitter gamma-aminobutyric acid (GABA), including benzodiazepines, as well as drugs that facilitate serotonergic transmission such as the serotonin (5-HT) uptake inhibitor zimelidine or the 5-HT autoreceptor blocker propranolol, decrease the aversive consequences of DPAG electrical stimulation $(2,3)$.

Intra-DPAG microinjections of excitatory amino acids such as glutamate also produce a flight reaction in rats (4). In contrast, the NMDA glutamate receptor antagonist AP-7, when injected into this structure, exerts a marked anxiolytic effect in rats submitted to the plus-maze test (5).

A glutamatergic action on NMDA receptors can stimulate the production of nitric oxide (NO) by the activation of the calmodulin-dependent enzyme, nitric oxide synthase (NOS) $(6,7)$. The DPAG displays high levels 
of NOS (8) and microinjections into this structure of two NOS inhibitors, L-NAME or L-NOARG, induced anxiolytic-like effects in the elevated plus-maze (9). In addition, injection into the DPAG of NO donors such as SIN-1 and DEA/NO produced a vigorous flight reaction in rats (10). These results suggest that NO may play a role in defense reactions mediated by the DPAG.

To further investigate this possibility we injected methylene blue (MB) into the DPAG of rats submitted to the elevated plus-maze test, an animal model of anxiety. MB has been used as an inhibitor of soluble guanylate cyclase (sGC) to demonstrate cGMPmediated processes (11), and there is evidence that NO may exert its biological effects by binding to the heme part of guanylate cyclase, causing an increase in cGMP levels (12).

Male Wistar rats (200-250 g) housed in pairs with free access to food and water in a temperature-controlled room $\left(23 \pm 1^{\circ} \mathrm{C}\right)$ were used in the experiments. The animals were submitted to stereotaxic surgery under tribromoethanol anesthesia $(2.5 \mathrm{mg} / \mathrm{kg}$, ip $)$ to implant a stainless steel guide cannula (0.7 mm OD) aimed at the DPAG (coordinates: $1.9 \mathrm{~mm}$ lateral to the right side of the lambda at an angle of $16^{\circ}$ with the sagittal plane, and $4.0 \mathrm{~mm}$ below the surface of the skull). The cannula was attached to the bone with stainless steel screws and acrylic cement. A stylet was introduced into the guide cannula to prevent obstruction. Seven days after surgery the animals received microinjections $(0.5 \mu \mathrm{l}$ in $30 \mathrm{~s})$ of either MB $(10,30$ or 100 $\mathrm{nmol}$ ) or saline and $10 \mathrm{~min}$ later were placed in the center of the plus-maze facing an enclosed arm. The maze consisted of two opposite open arms $(50 \times 10 \mathrm{~cm})$, crossed at right angles by two arms of the same dimensions, enclosed by $40-\mathrm{cm}$ high walls with no roof. It was elevated $50 \mathrm{~cm}$ from the floor and had a 1-cm high edge made of plexiglas surrounding the open arms. The number of entries and time spent in open and enclosed arms of the maze were recorded for $5 \mathrm{~min}$. After the behavioral tests, the rats were sacrificed under deep anesthesia and their heads perfused with isotonic saline followed by $10 \%$ formalin. A dental needle was inserted through the guide cannula and a $0.2-\mu \mathrm{mi}$ croinjection of Evans blue was performed. The brains were removed, immersed in $10 \%$ formalin for 3 days and 50- $\mu$ m frozen sections were cut with a cryostat (Cryocut 1800). Injection sites were localized in diagrams of the Paxinos and Watson rat brain atlas. The data for eight rats who received injections outside the DPAG were excluded from the analysis.

For statistical analysis the percentage of open arm entries (100 x open/total entries) and of time spent in the open arms (100 x open/open + enclosed) was calculated for each rat. These data, together with the number of enclosed arm entries, were analyzed by one-way analysis of variance (ANOVA) followed by the Duncan test for multiple comparisons.

As shown in Figure 1, the injection of 30 nmol MB significantly increased the percentage of time spent in the open $\operatorname{arm}\left(\mathrm{F}_{3,54}=\right.$ 3.52; $\mathrm{P}<0.02$, Duncan test, $\mathrm{P}<0.05$, compared to control) and tended to increase the percentage of open arm entries $\left(\mathrm{F}_{3,54}=1.98\right.$; $\mathrm{P}<0.10$, Duncan test, $\mathrm{P}<0.10$, compared to control), but did not change the number of enclosed arm entries ( $\mathrm{P}>0.10$, ANOVA). The results, therefore, suggest that $\mathrm{MB}$ has anxiolytic properties (13). The dose-response curve, however, had an inverted U shape, with both higher and lower doses being ineffective. Similar results were recently obtained with the intravenous administration of MB (14).

Several of the biological effects of $\mathrm{MB}$ have been related to the antagonism of NO action. For example, MB inhibits sGC, attenuating the NO-mediated increase in cGMP levels $(11,12,15)$. It can also inhibit other iron-containing enzymes such as NOS, acting as a direct NOS inhibitor (16), or directly 
antagonize NO through the generation of superoxide anions derived from its oxidative metabolism (17).

Reinforcing a possible involvement of $\mathrm{NO}$ in the anxiolytic effect of MB, the exposure of rats to a predator was accompanied by an increase in the production of $\mathrm{NO}$ and cGMP in the DPAG (18) and NO donors microinjected into this region induced a vigorous flight reaction (10). Moreover, two NOS inhibitors, L-NAME and L-NOARG, after systemic (19) or intra-DPAG administration (10) showed anxiolytic effects. However, the anxiolytic dose range for these inhibitors was also limited, with the doseeffect curves showing an inverted $U$ shape.

NO has been proposed as a transduction mechanism of NMDA receptor-mediated neurotransmission $(6,7)$ and antagonists of NMDA receptors produce anxiolytic effects in the DPAG $(5,20)$. The present results, showing an anxiolytic effect of an NO antagonist, support this proposition.

In conclusion, the present results show an anxiolytic effect of MB microinjected into the DPAG, supporting the involvement of $\mathrm{NO}$ in the modulation of defensive reac-

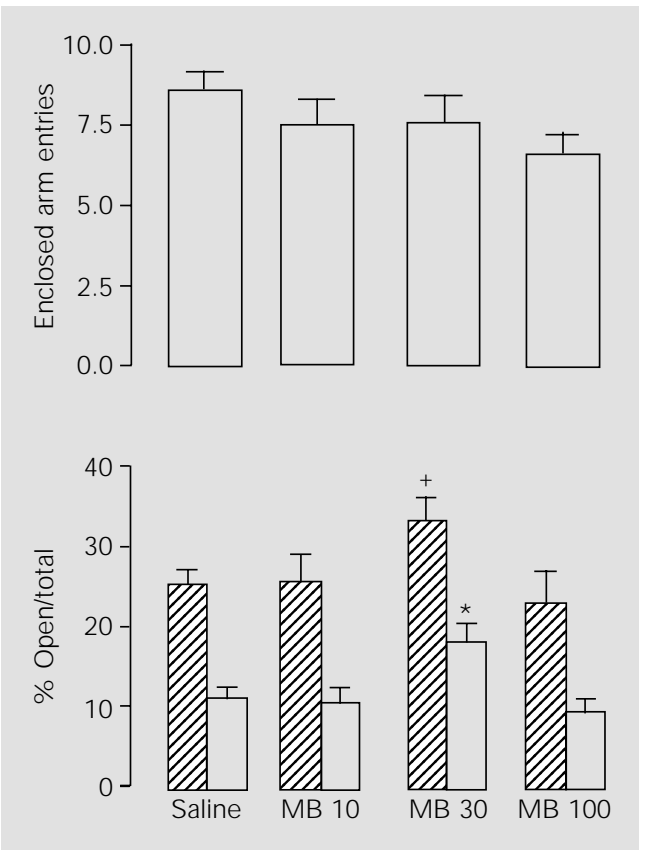

Figure 1 - Anxiolytic effect of intra-DPAG microinjection of methylene blue $(\mathrm{MB})$ in rats tested in the elevated plusmaze. A volume of $0.5 \mu \mathrm{l}$ of saline $(N=22)$ or $M B(10,30$ or $100 \mathrm{nmol}, \mathrm{N}=12 /$ group) was injected over a period of $30 \mathrm{~s}$. Ten minutes later the animals were placed in the center of the maze. In the upper panel the columns represent the mean number of enclosed arm entries. In the lower panel the hatched columns represent the mean percentage of entries into open arms and the open columns the mean percentage of time spent in these arms. Bars refer to the SEM of the groups. $* P<0.05$ and $+P<0.10$ compared to control (ANOVA followed by the Duncan test).

tion in this region.

\section{Acknowledgments}

The authors acknowledge the helpful technical support provided by J.C. de Aguiar.

\section{References}

1. Graeff FG (1991). Neurotransmitters in the dorsal periaqueductal gray and animal models of panic anxiety. In: Briley $M$ \& File SE (Editors), New Concepts in Anxiety. MCMillian, London, 288-312.

2. Schenberg LC, De Aguiar J C \& Graeff FG (1983). GABA modulation of defence reaction induced by brain electrical stimulation. Physiology and Behavior, 31: 429437.

3. Graeff FG, Silveira MC, Nogueira RL, Audi EA \& Oliveira RM (1993). Role of amygdala and periaqueductal gray in anxiety and panic. Behavioural Brain Research, 58: 123-127.

4. Bandler R (1988). Brain mechanisms of aggression as revealed by electrical and chemical stimulation: suggestion of a central role for the midbrain periaqueductal gray region. In: Epstein $A \&$ Horrison $A$ (Editors), Progress in Psychobiology and
Physiological Psychology. Vol. 13. Academic Press, New York, 67-154.

5. Guimarães FS, Carobrez AP, De Aguiar J C \& Graeff FG (1991). Anxiolytic effect in the elevated plus-maze of NMDA receptor antagonist AP7 microinjected into the dorsal periaqueductal gray. Psychopharmacology, 103: 91-94.

6. Garthwaite J, Charles SL \& Chess-Williams R (1988). Endothelium-derivated relaxing factor release on activation of NMDA receptors suggests role as intercellular messenger in the brain. Nature, 336: 385-388.

7. Garthwaite J (1991). Glutamate, nitric oxide and cell-cell signalling in the nervous system. Trends in Neurosciences, 14: 6067.

8. Vincent SR \& Kimura H (1992). Histochemical mapping of nitric oxide synthase in the rat brain. Neuroscience, 46:
755-784.

9. Guimarães FS, de Aguiar J C, Del Bel EA \& Ballejo GO (1994). Anxiolytic effect of nitric oxide synthase inhibitors microinjected into the dorsal central gray. NeuroReport, 5: 1929-1931.

10. Del Bel EA, de Oliveira RMW \& Guimarães FS (1998). Role of nitric oxide on emotional and motor behaviour. In: Torre V \& Nicholls J (Editors), Proceedings of the NATO ASI School 'Neuronal Circuits and Networks'. Springer Verlag, Berlin, 109-124.

11. Ignarro LJ \& Kadowitz PJ (1985). The pharmacological and physiological role of cyclic GMP in vascular smooth muscle relaxation. Annual Review of Pharmacology and Toxicology, 25: 171-191.

12. Moncada S, Palmer RMJ \& Higgs EA (1991). Nitric oxide: physiology, pathophysiology and pharmacology. Pharmaco- 
logical Reviews, 43: 109-142.

13. File SE (1992). Behavioural detection of anxiolytic action. In: Elliot J M, Heal DJ \& Marsden CA (Editors), Experimental Approaches to Anxiety and Depression. J ohn Wiley \& Sons, New York, 25-44.

14. Eroglu L \& Çaglayan B (1997). Anxiolytic and antidepressant properties of methylene blue in animal models. Pharmacological Research, 36: 381-385.

15. Kelner MJ , Bagnell R, Hale B \& Alexander NM (1988). Methylene blue competes with paraquat for reduction by flavo-enzymes resulting in decreased superoxide production in the presence of heme pro- teins. Archives of Biochemistry and Biophysics, 262: 422-426.

16. Mayer B, Brunner F \& Schmidt K (1993). Inhibition of nitric synthases by methylene blue. Biochemical Pharmacology, 45: 367-374.

17. Wolin MS, Cherry PD, Rodenburg JM, Messina EJ \& Kaley G (1990). Methylene blue inhibits vasodilatation of skeletal muscle arterioles to acetylcholine and nitric oxide via the extracellular generation of superoxide anion. J oumal of Pharmacology and Experimental Therapeutics, 254: 872-876.

18. Chiavegatto $C$, Scavone $C \&$ Canteras NS
(1998). Nitric oxide synthase activity in the dorsal periaqueductal gray of rats expressing innate fear response. NeuroReport, 4: 571-576.

19. Volke V, Koks S, Vasar E, Bourin M, Bnedwyn J \& Mannisto PT (1995). Inhibition of nitric synthases causes anxiolyticlike behaviour in an elevated plus-maze. NeuroReport, 6: 1413-1416.

20. Matheus MG, Nogueira RL, Carobrez AP, Graeff FG \& Guimarães FS (1994). Anxiolytic effect of glycine antagonists microinjected into the dorsal periaqueductal grey. Psychopharmacology, 113: 565-569. 